\title{
Anticoking Coatings for High Temperature Petrochemical Reactors
}

\author{
P. Broutin ${ }^{1}$, F. Ropital ${ }^{2}$, M.-F. Reyniers ${ }^{3}$ and G.-F. Froment ${ }^{3}$ \\ 1 Institut français du pétrole, CEDI René Navarre - Solaize BP 3, 69390 Vernaison Cedex - France \\ 2 Institut français du pétrole, 1 et 4, avenue de Bois-Préau, 92852 Rueil-Malmaison Cedex - France \\ 3 Laboratorium voor Petrochemische Techniek, Universiteit, B9000 Gent-Belgium
}

Résumé - Revêtements pour réacteurs pétrochimiques à cokage réduit - La formation de coke est un problème crucial pour de nombreux procédés pétrochimiques.

Ralentir le cokage permet de réduire la fréquence des décokages et de limiter la dégradation du transfert thermique. Un des moyens envisageables pour réduire le cokage est le dépôt d'un revêtement à la paroi de ces réacteurs. La mise au point de tels revêtements a fait l'objet d'un projet de recherche européen Brite-Euram, pour lequel le vapocraquage a été la principale application considérée.

Au cours de ce projet, l'Institut français du pétrole a développé une méthodologie pour l'étude de tels revêtements. Une première sélection de matériaux et de techniques de revêtement a été opérée au travers d'un cahier des charges et des informations disponibles dans la littérature. Les revêtements retenus ont ensuite été évalués au travers d'un test de cyclage thermique et d'un test de cokage réalisés dans des conditions proches des conditions industrielles.

Pour le test de cokage, il a été mis au point un microréacteur agité permettant d'opérer jusqu'à $950^{\circ} \mathrm{C}$. Les vitesses de cokage obtenues sur des éprouvettes revêtues ont été comparées à celles obtenues sur des éprouvettes en alliages réfractaires non revêtues : une réduction par un facteur 3 de la vitesse asymptotique de cokage a été observée pour le revêtement le plus prometteur.

En parallèle, le Laboratorium voor Petrochemische Techniek a entrepris l'étude cinétique du cokage sur des alliages réfractaires non revêtus, ce qui a permis de modéliser le dépôt de coke sur ces matériaux.

Mots-clés : revêtement, vapocraquage, coke.

\begin{abstract}
Anticoking Coatings for High Temperature Petrochemical Reactors - Coke deposition is a major problem for several refinery and petrochemical processes, among which steam cracking for ethylene production.

Decreasing coking rates will reduce decoking frequency and will also decrease heat transfer degradation. For these processes, a means of reducing coking phenomena is the application of anticoking coatings on the reactor walls. For this purpose a methodology was developed under a CEC Brite-Euram project with steam cracking as the main application.

A first selection of the coatings and their techniques of deposition was performed according to their composition (non catalytic compounds), their resistance to carburization and oxidation and also according to the nature of the substrate. The feasibility of coating deposition was studied for small diameter furnace tubes and the techniques were perfected in particular with respect to the physicochemical characterization of the coatings and their resistance during thermal cycling and
\end{abstract}


coking-decoking cycles. For the thermal cycling and the coking evaluation, industrial conditions were reproduced as closely as possible.

For coking tests, a microreactor with complete mixing of the gas phase was developed for temperatures up to $950^{\circ} \mathrm{C}$. The coking behavior of the coated samples was compared with conventional refractory alloys: reduction of the coking rate by a factor of 3 was measured with the most promising coating. This work was completed by the kinetic modelling of coking on uncoated materials.

Keywords: coating, steam cracking, coke.

\section{INTRODUCTION}

This paper summarizes the results obtained within the framework of the European Brite-Euram project BRE2CT92-0190 from 1 January 1993 up to 31 December 1996 [1, 2]. The aim of this project was to develop new coatings that could inhibit coke deposition on the inside walls of the reactors used for hydrocarbons thermal cracking. Coking inhibition reduces the frequency of shutdowns for decoking. Since steam cracking for olefins production is the main process for which anticoking coatings would allow significant savings, this petrochemical process was the only application considered. Thermal cracking units are typically constructed of heat resistant $\mathrm{Fe}-\mathrm{Ni}-\mathrm{Cr}$ alloys. An inherent problem associated with these alloys is their tendency to promote the deposition of carbonaceous materials. The carbon deposition process during thermal cracking is a complex phenomenon, mainly consisting of catalytic carbon formation and radical growth of coke from existing layers onwards, although gas phase coking cannot be excluded for heavy feeds. Coke deposition in thermal cracking units is known to depend not only on the chemical composition of the alloy, but also on the surface composition. The coking potential of the alloy can be modified by coating the reactor walls.

Three different types of coatings, produced by 4 different SMEs, were studied:

- ceramic and metallic plasma sprayed coatings;

- packed cementation coatings;

- CVD coatings.

In this project, IFP was in charge of the screening tests on the coated samples:

- thermal cycling tests to simulate thermal shocks in industrial conditions;

- coking tests in a micropilot in order to compare the coking rates of the coatings and the substrate alone, under reference conditions;

- physicochemical characterization of the samples before and after tests performed in collaboration with a university laboratory.

Within the framework of this project, LPT Gent was in charge of modeling coke deposition. With such models, it would be possible to predict coking rates in industrial reactors and consequently to estimate the benefit of coke inhibition.

\section{METHODOLOGY}

The substrate to be coated was one of the most recent HPmodified alloys used to produce ethylene furnace tubing [3]. The refractory alloy is an austenitic ASTM A297 HP modified steel cast by centrifugation with the following composition (weight \%):

$\begin{array}{llllll}\mathrm{C} & \mathrm{Mn} & \mathrm{Si} & \mathrm{Ni} & \mathrm{Cr} & \text { Additions } \\ 0.5 & 1.3 & 1.5 & 35 & 26 & \mathrm{Nb}, \mathrm{Ti}, \mathrm{Zr}\end{array}$

With such a composition, tube skin temperature of up to $1160^{\circ} \mathrm{C}$ is allowed.

Prior to the beginning of this research project, a first selection of the coatings and the coating techniques was made from the literature [4-8] based on the following coating specification:

- nature of the substrate;

- inhibition of coke deposition;

- purity (no trace of nickel or iron which are catalysts for the coking reactions);

- smoothness (coke deposition increases with roughness);

- resistance to high temperature $\left(800-1200^{\circ} \mathrm{C}\right)$;

- resistance to carburization (normal operating conditions) and oxidation (decoking practiced under steam + air and air would be limited but would remain present);

- no open porosity;

- adhesion to the substrate;

- resistance to thermal shocks;

- shape of the industrial pieces to be coated (tube with small diameters $(25$ to $100 \mathrm{~mm})$ and substantial length $(1 \mathrm{~m}$ and more)).

The following coating techniques were studied:

- plasma spraying of ceramic and metallic powders;

- packed cementation;

- chemical vapor deposition.

A first stage consisted in screening tests carried out on small flat coated coupons $(10 \cdot 8 \cdot 1 \mathrm{~mm}$ with a $2 \mathrm{~mm}$ hole):

- a thermal cycling test in a muffle furnace to simulate thermal shocks in industrial conditions;

- a coking test in a microreactor in order to compare the coking rates of the coatings and the substrate alone in reference conditions;

- physicochemical characterization of the samples before and after tests. 
For the selected coatings, a second stage consisted in coating the inner walls of tube elements $100 \mathrm{~mm}$ in diameter and $100 \mathrm{~mm}$ in length and testing the coated tube elements:

- a thermal cycling test in a muffle furnace to simulate thermal shocks in industrial conditions;

- physicochemical characterization of the samples before and after tests.

At the same time, LPT Gent carried out kinetic experimentation and modeling. A new microreactor with complete mixing of the gas phase was constructed for kinetic experimentation at temperatures up to $950^{\circ} \mathrm{C}$. Kinetic experiments were performed by $L P T$ mainly on 3 materials and with 3 different feed stocks. Modeling of the coking rate on 2 metallic materials was also performed by LPT Gent.

\section{EQUIPMENT AND EXPERIMENTAL PROCEDURE}

\subsection{Thermal Cycling Tests}

Thermal cycling was carried out by IFP in a muffle furnace equipped with air injection. To simulate thermal shocks in industrial steam cracking tubes, samples were heated and cooled from ambient temperature to $1000^{\circ} \mathrm{C}$ with a rate of $500^{\circ} \mathrm{C} / \mathrm{h}$.

\subsection{Coking Tests}

A microreactor with complete mixing of the gas phase was built for the coking tests. A flat coupon of the alloy and coating to be tested was suspended in its centre from one arm of an electrobalance.

The main parts of this coking device are shown in Figure 1. Water is fed by means of a Watson-Marlow peristaltic pump at a flow rate of $20 \mathrm{ml} / \mathrm{h}$. An Ismatec peristaltic pump is used at a flow rate of $60 \mathrm{ml} / \mathrm{h}$ for the hydrocarbon. The mixture is then evaporated and preheated up to a temperature of $270^{\circ} \mathrm{C}$ before entering the reactor preheater.

A Setaram TG 92 microbalance is used in order to get sensitive and continuous measurement of coke deposition on the sample. It is monitored by means of an Epson 386 PC.

On-line analysis of the gas phase is performed by an IR $\mathrm{CO}$ analyser and three gas chromatographs. The $\mathrm{CO}$ analyser is a Cosma Beryl 100 device which can measure $\mathrm{CO}$ content from 1 to $10 \%$. A Girdel TCD chromatograph is mounted with a Porapak column to detect $\mathrm{N}_{2}$ and $\mathrm{H}_{2}$. Another Girdel TCD chromatograph is also set up to analyse $\mathrm{N}_{2}, \mathrm{H}_{2}, \mathrm{CH}_{4}$ and $\mathrm{CO}$ with a HP carbosphere column. The third chromatograph is a Hewlett Packard FID 5890: its Pona column allows analysis of compounds from $\mathrm{C} 1$ to styrene.

The following experimental procedure was established in connection with LPT Gent:

- a reference surface preparation was used for the coated and uncoated samples (polishing of the uncoated samples, cleaning, handling);

- preheating was performed under nitrogen for $2 \mathrm{~h}$ on cleaned samples;

- the flow rates were fixed at $60 \mathrm{ml} / \mathrm{h}$ for the $n$-hexane feed and $20 \mathrm{ml} / \mathrm{h}$ for the water;

- the temperature was fixed at $800^{\circ} \mathrm{C}$.

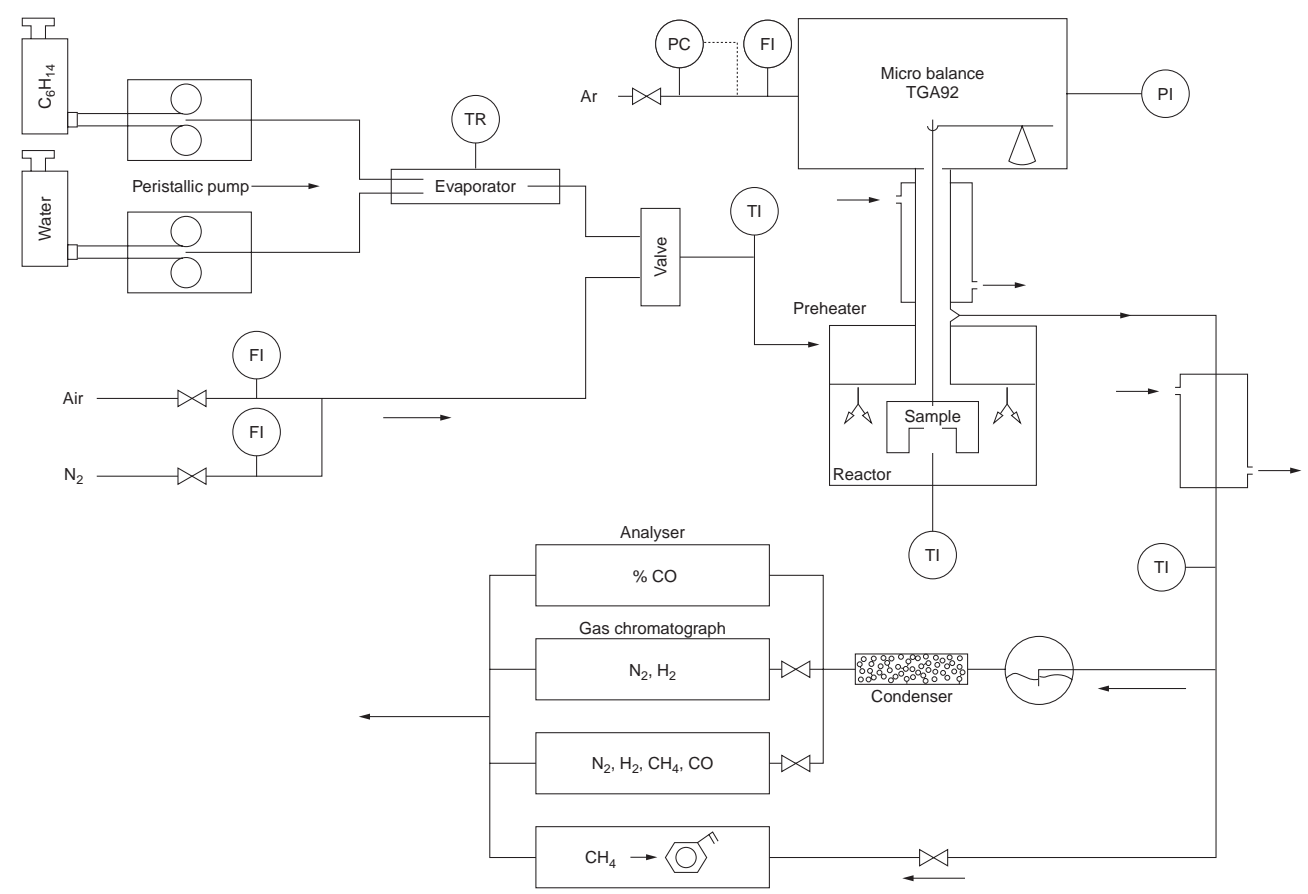


Under these reference conditions, the $n$-hexane conversion was on the order of $30 \%$.

The main coking parameters, that were analysed and compared, were $v_{i}$ the asymptotic coking rate for the $i^{\text {th }}$ coking cycle of the sample after $5 \mathrm{~h}$ of experimentation (the mechanism that corresponds to the asymptotic coking rate is the non-catalytic heterogeneous mechanism which is the most important one in describing the growth of the coke layer) and $c_{i}$ the mass of coke deposited after $5 \mathrm{~h}$ of operation. Figure 2 presents coking curves for the substrate, the packed cementation and CVD coatings.

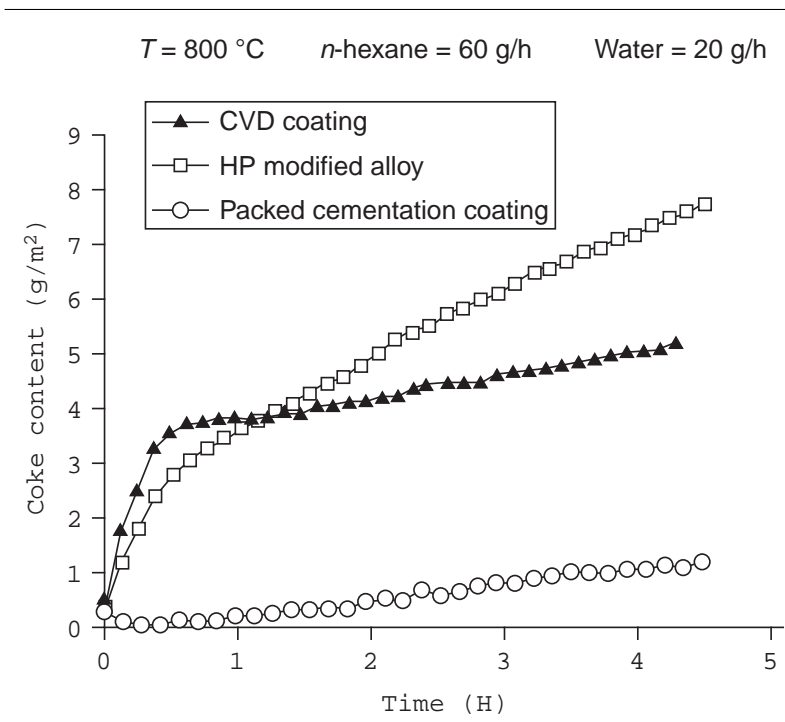

Figure 2

Coking plots of the HP-modified alloy, packed cementation and CVD coatings.

\subsection{Physicochemical Characterization of the Samples}

Physicochemical characterization by IFP consisted mainly of visual and metallographic examinations of cross sections by optical and scanning electronic microscopy (SEM) and microprobe analysis.

\subsection{Kinetic Experimentation}

To carry out kinetic experimentation up to $950^{\circ} \mathrm{C}$, a reactor was constructed by LPT Gent (Fig. 3). The experimental set up consists of a feed section, a reactor and electrobalance section and an analysis section (see Figure 4 for a schematic representation of the set up). With respect to the previously described reactor, this new version contains a modified preheat section [9].

The feed consists of a hydrocarbon stream and a dilution stream. The liquid hydrocarbon is fed by pressurizing a glass vessel with nitrogen and forcing the liquid through a thermostated capillary (length $=12 \mathrm{~m}$, internal diameter $=0.5 \mathrm{~m}$ ). The flow rate is measured by means of a calibrated burette connected in parallel with the vessel. For the experiments with steam dilution, water is fed by means of a Pharmacia-P500 pump. Both streams are preheated and mixed in an evaporator at $190^{\circ} \mathrm{C}$. The evaporator is filled with glass pearls to ensure a steady flow of the feed. The hydrocarbon-diluent mixture is then sent to the reactor.

The inlet zone of the reactor is designed to ensure complete mixing of the gas phase. The reactor is placed inside an electric furnace. The amount of coke is continuously monitored by means of a Cahn 2000 electrobalance. The effluent leaves the reactor through the tube containing the suspension wire and then through a side exit. A flow of carbon dioxide prevents the effluent from flowing into the balance chamber. The effluent is cooled in a heat exchanger and flows through a cyclone in which tars are separated from the gas and in which nitrogen, the internal standard for the GC-analysis, is added.

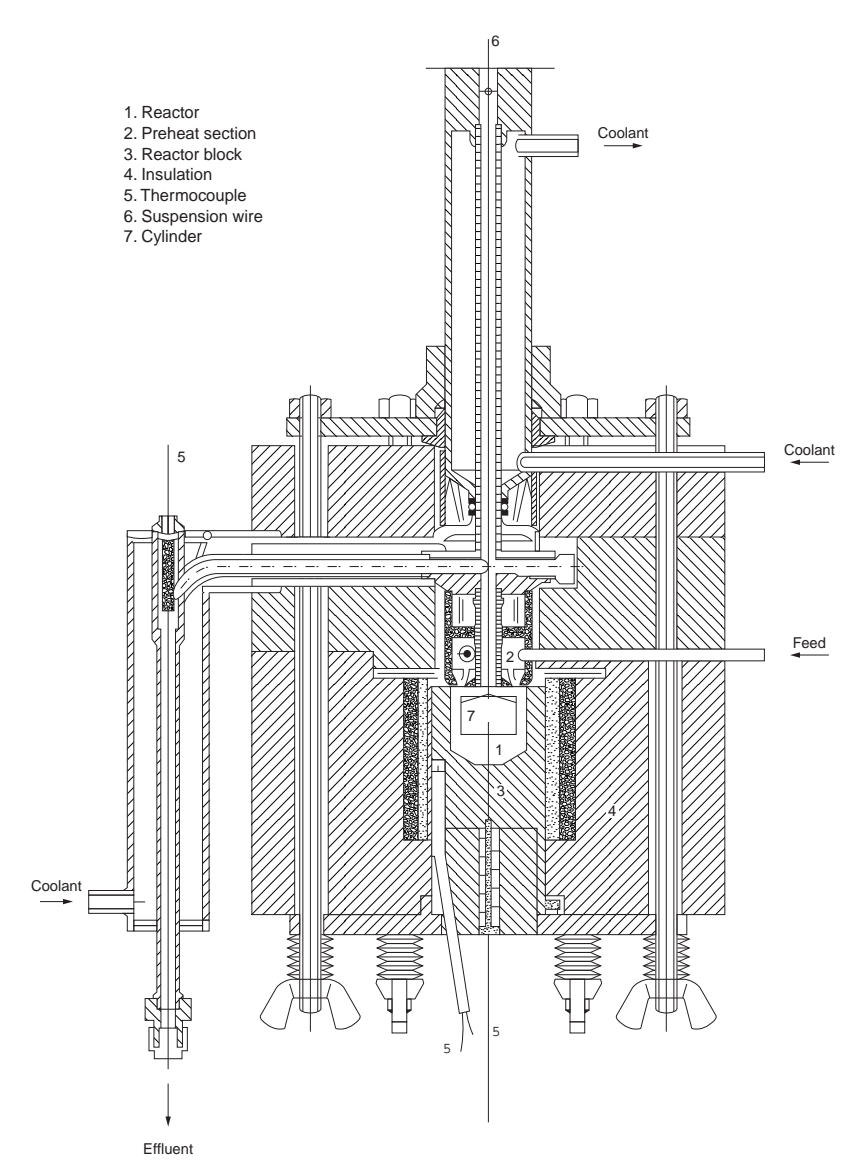

Figure 3

LPT Gent reactor with complete mixing of the gas phase. 


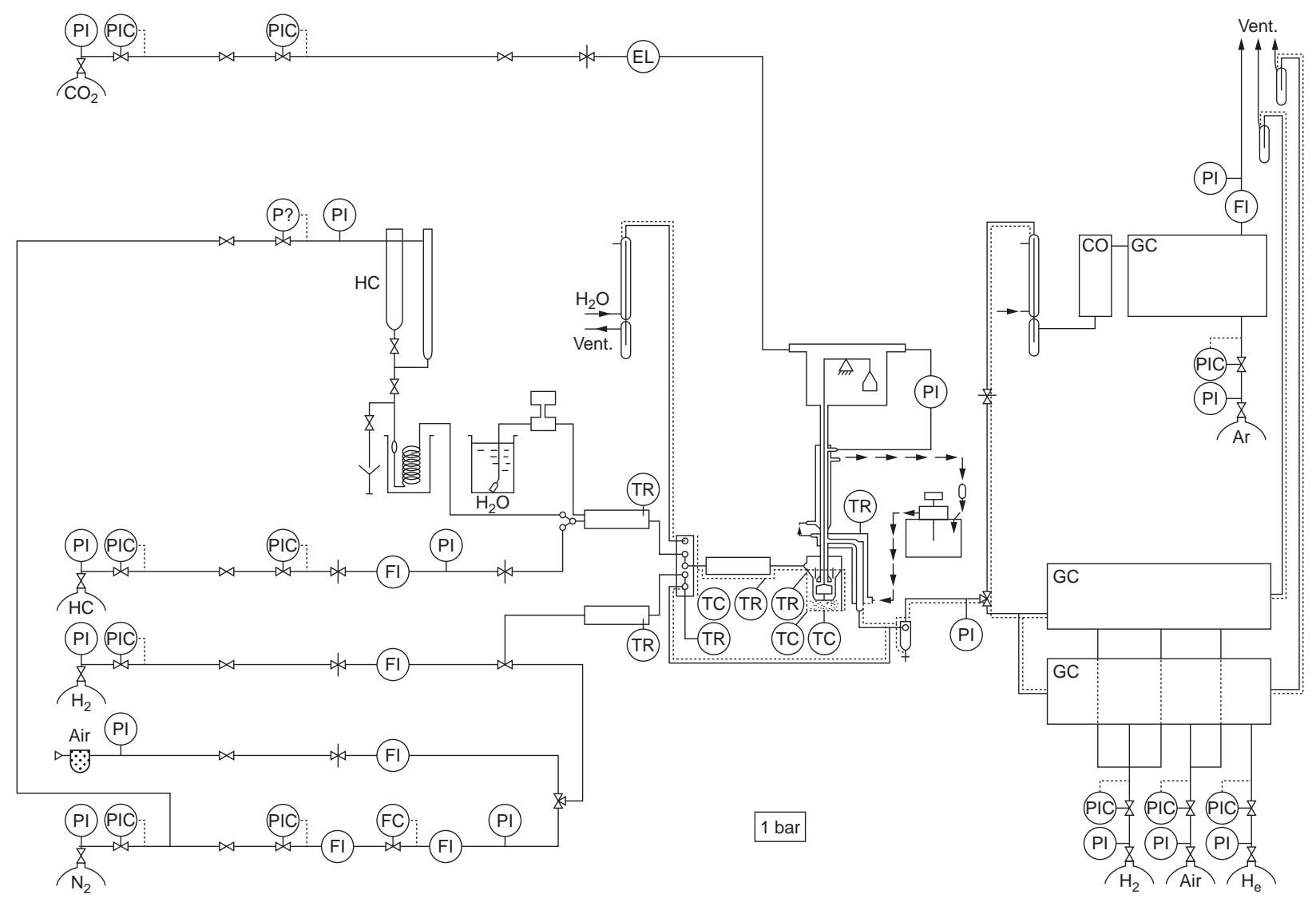

Figure 4

LPT Gent experimental set up.

The analysis section consists of two parts:

- continuous analysis for CO with a Teledyne IRA, model 711, infrared analyser;

- on-line gas chromatographic analysis of the effluent using 3 gas chromatographs (respectively Packard 417 A, Packard 417 B, Varian 3400).

\section{MAIN EXPERIMENTAL RESULTS}

\subsection{Thermal Testing of Flat Coupons}

Three series of experiments were carried out:

- 1 thermal cycle;

- 7 thermal cycles;

- 15 thermal cycles.

The visual examination of the samples after thermal cycling was in accordance with the physicochemical characterization of the samples before the test: only some plasma-sprayed coatings were found to be non-adherent. However, for the APS technique, coated flat samples are perhaps not really representative of inner coated tubes from the standpoint of resistance to thermal shocks.

The characterization of coated flat samples was also performed after thermal testing. For each coating, the thickness, porosity, adhesion and composition were compared after and before thermal cycling:

- for plasma sprayed coatings, no significant degradations were observed after thermal cycles on the coatings with the best physicochemical characteristics;

- for packed cementation coatings, no significant degradations were observed after thermal cycles;

- after thermal cycling, CVD coatings we refound to be homogeneous. They showed good adhesion.

These observations were the same for 1,7 or 15 cycles.

\subsection{Coking Tests}

\subsubsection{Uncoated Coupons}

Preliminary coking tests were performed on uncoated materials: HP modified alloy, sintered $\alpha$ silicon carbide. 
The experiments were performed at least 5 times with the same sample and a good reproducibility was observed. The following coking rates were measured under reference conditions:

- HP modified alloy: $0.9 \mathrm{~g} / \mathrm{m}^{2} \mathrm{~h}$

- $\alpha$ silicon carbide: $\quad 0.2 \mathrm{~g} / \mathrm{m}^{2} \mathrm{~h}$.

The main difference in the coking behaviour of the 2 materials was more coke deposit on the metallic sample during the first minutes of the experiments due to the catalytic effect.

\subsubsection{Coated Coupons}

All the coated samples were tested under reference conditions. Coking and decoking cycles were performed and the coking sensitivity was also measured after decoking. Decoking was carried out with air. The coatings had to sustain coking and also decoking with air; the adhesion behaviour of the coatings was exactly the same as that observed during the thermal cycling test.

\section{Plasma Sprayed Coatings}

For plasma sprayed coatings, adhesion was not maintained. The best results were obtained for polished samples. For the $\mathrm{Cr}_{2} \mathrm{O}_{3}$ based powder $\left(92 \mathrm{Cr}_{2} \mathrm{O}_{3}-5 \mathrm{SiO}_{2}-3 \mathrm{TiO}_{2}\right)$, the coking rate was of the same magnitude as on the HP-modified alloy (Table 1).

\section{TABLE 1}

Coking test results for plasma sprayed coatings

\begin{tabular}{|c|c|c|c|c|c|}
\hline \multirow[b]{2}{*}{ Coating } & \multirow[b]{2}{*}{ Polishing } & \multicolumn{2}{|c|}{ 1st coking } & \multicolumn{2}{|c|}{ 2nd coking } \\
\hline & & $\begin{array}{c}v_{1} \\
\mathrm{~g} / \mathrm{m}^{2} \mathrm{~h}\end{array}$ & $\begin{array}{c}c_{1} \\
\mathrm{~g} / \mathrm{m}^{2} \mathrm{~h}\end{array}$ & $\begin{array}{c}v_{2} \\
\mathrm{~g} / \mathrm{m}^{2} \mathrm{~h}\end{array}$ & $\begin{array}{c}c_{2} \\
\mathrm{~g} / \mathrm{m}^{2}\end{array}$ \\
\hline \multirow{2}{*}{$\begin{array}{l}92 \mathrm{Cr}_{2} \mathrm{O}_{3}-5 \mathrm{SiO}_{2}-3 \mathrm{TiO}_{2} \\
\text { Andry } 6462\end{array}$} & $\mathrm{P}$ & 0.8 & 4 & 0.8 & 4 \\
\hline & NP & 1.4 & 10 & 1.1 & 9 \\
\hline Pure $\mathrm{Cr}_{2} \mathrm{O}_{3}$ powder & NP & 4 & 35 & 3.9 & 32 \\
\hline \multirow[t]{2}{*}{ Pure $\mathrm{Cr}$ powder } & $\mathrm{P}$ & 1.6 & 10 & & \\
\hline & NP & 1.6 & 10 & 2.7 & 25 \\
\hline $\mathrm{Al}_{2} \mathrm{O}_{3}$ & $\mathrm{P}$ & 0.7 & 3 & 2.4 & 20 \\
\hline Metco 105 & NP & 2.6 & 16 & 2.7 & 24 \\
\hline \multirow{2}{*}{$\begin{array}{l}95 \mathrm{Al}_{2} \mathrm{O}_{3}-3 \mathrm{TiO}_{2}-2 \mathrm{SiO}_{2} \\
\text { Metco } 101 \mathrm{BNS}\end{array}$} & $\mathrm{P}$ & 1.2 & 9 & 1.7 & 11 \\
\hline & NP & 1.6 & 10 & 1.4 & 10 \\
\hline $\mathrm{Cr}-2 \mathrm{Si}$ & $\mathrm{P}$ & 1.3 & 10 & 1.9 & 15 \\
\hline \multicolumn{6}{|l|}{ Metco 66F NS 1} \\
\hline $52 \mathrm{Co}-28 \mathrm{Mo}-17 \mathrm{Cr}-3 \mathrm{Si}$ & $P$ & 2.2 & 20 & 1.9 & 15 \\
\hline \multicolumn{6}{|l|}{ Metco 68F NS 1} \\
\hline $93 \mathrm{ZrO}_{2}-7 \mathrm{Y}_{2} \mathrm{O}_{3}$ & NP & 4 & 35 & 3.9 & 34 \\
\hline \multicolumn{6}{|l|}{ Amperit 825.1} \\
\hline $88 \mathrm{Al} 12 \mathrm{Si}$ & NP & 2.7 & 26 & 3.0 & 28 \\
\hline
\end{tabular}

: asymptotic coking rate for the $i^{\text {th }}$ coking of the sample

$c_{i}$ : mass of coke deposited after $5 \mathrm{~h}$ of coking testing

$\mathrm{P:} \quad$ polished sample

NP: unpolished sample.

\section{Packed Cementation Coatings}

The best results were obtained with the $\mathrm{Cr}$ based cement (Table 2).

TABLE 2

Coking test results for packed cementation and CVD coatings

\begin{tabular}{l|c|c|c|c}
\hline \multirow{2}{*}{\multicolumn{1}{c|}{ Coating }} & \multicolumn{2}{c|}{ 1st coking } & \multicolumn{2}{c}{ 2nd coking } \\
\cline { 2 - 5 } & $\begin{array}{c}v_{1} \\
\mathrm{~g} / \mathrm{m}^{2} \mathrm{~h}\end{array}$ & $\begin{array}{c}c_{1} \\
\mathrm{~g} / \mathrm{m}^{2}\end{array}$ & $\begin{array}{c}v_{2} \\
\mathrm{~g} / \mathrm{m}^{2} \mathrm{~h}\end{array}$ & $\begin{array}{c}c_{2} \\
\mathrm{~g} / \mathrm{m}^{2}\end{array}$ \\
\hline Packed cementation coatings & & & & \\
Cr based & 0.25 & 1.0 & 0.20 & 0.8 \\
Cr, Al based & 0.44 & 2.1 & 0.47 & 2.5 \\
Al, Si based & 0.50 & 3.5 & 0.50 & 3.7 \\
Al, TI based & 0.40 & 1.9 & 1.4 & 7.5 \\
\hline CVD coatings & & & & \\
TiC only & 0.46 & & 0.47 & \\
TiC + SiC & 0.29 & 1.1 & 0.27 & 1 \\
\hline
\end{tabular}

asymptotic coking rate for the $i^{\text {th }}$ coking of the sample

$c_{i}$ : mass of coke deposited after $5 \mathrm{~h}$ of coking testing.

\section{CVD Coatings}

CVD coatings of $\mathrm{TiC}$ alone and $\mathrm{TiC}+\mathrm{SiC}$ were evaluated. The best results were obtained with the sandwich coating $\mathrm{TiC}+\mathrm{SiC}$ (Table 2).

For CVD coatings, no catalytic coking was observed. For the $\mathrm{TiC}+\mathrm{SiC}$ coating, the asymptotic coking rate was three times lower than on the HP-modified alloy (coking tests were performed at $30 \%$ conversion and not $60-70 \%$, which are industrial conversions. Under industrial conditions, segregation of the materials would probably be more pronounced).

\subsubsection{Preferred Coatings}

Very low coking rates were observed with the following coatings:

- chromium packed cementation coating: $0.25 \mathrm{~g} / \mathrm{m}^{2} \mathrm{~h}$;

- TiC + SiC CVD coating: $0.3 \mathrm{~g} / \mathrm{m}^{2} \mathrm{~h}$.

These values compare very favourably with those obtained in the same reference conditions with non coated HP-modified alloy: $0.9 \mathrm{~g} / \mathrm{m}^{2} \mathrm{~h}$.

For plasma coatings, higher coking rates than on the uncoated substrate were found. The flat sample geometry needed by the micropilot for coking tests gave rise to difficulties in obtaining good quality coating especially with plasma spraying. As a result, these coatings could not be tested from the standpoint of coking behavior.

\subsection{Characterization of the Samples after the Coking Test}

Characterization was mainly performed by metallographic examination, scanning electronic microscopy (SEM) and microprobe analysis. 


\section{Plasma Sprayed Coatings}

On visual examination, plasma sprayed coatings appeared very black after the coking test. On micrographic examination, high porosity and coke filaments on the surface as well as cracks in the length and thickness of the coated samples were noticed. This suggests that these phenomena are the cause of the high coking rates observed in the microreactor.

\section{Packed Cementation Coatings}

For chromium based coatings, closed porosity in the core was observed. The adhesion to the substrate is very good. Locally some segregation of silicon was observed. Micrographic examination, revealed that, when the coating presents defects, coke grows on the defects.

\section{CVD Coatings}

The coatings are uniform and have a good adhesion to the steel substrate.

\subsection{Thermal Testing of Coated Tube Pieces}

In the second stage of this project, the following tube pieces were coated on the inside:

- tube elements $100 \mathrm{~mm}$ long cut in a $120 \cdot 100 \mathrm{~mm}$ tube made of HP-modified alloy;

- rings $10 \mathrm{~mm}$ high cut in a $120 \cdot 100 \mathrm{~mm}$ tube made of HPmodified alloy.

All the samples were machined (flat samples on the two faces, tubes on the inside surface only) to obtain a surface similar to that of industrial tubes, i.e. a roughness of 63 RMS.

Thermal testing of the coated tube pieces was performed by IFP under the same conditions as for the flat samples (see Section 2 for set up and operating procedure). All the tube elements from coating manufacturers were cycled but some coated rings were not cycled to serve as blanks. The tested coated pieces were subjected to 16 thermal cycles.

After the thermal cycles, the following was observed:

$\mathrm{Cr}_{2} \mathrm{O}_{3}$ powder plasma sprayed: coating non adherent

Cr powder plasma sprayed: coating non adherent

Cr based packed cementation coating: no visible defect

CVD coating on $100 \mathrm{~mm}$ elements: no coating on the edgecentral dark colour

CVD coating on $10 \mathrm{~mm}$ rings: no visible defect.

For plasma sprayed coatings, resistance to thermal shocks was weak.

For packed cementation coatings, adhesion was good.

For CVD coatings, the results obtained on the tubes can be explained by the large size of the tube elements compared to the size of the furnace: the diameter and length of the tube elements are close to the inner diameter of the deposition chamber. The reactive gases probably undergo significant chemical reactions in the gas phase along the tube, so that the chemical composition and thickness of the coating are variable. A larger CVD reactor would be necessary to coat these tube elements.

For long tube coating (up to $6 \mathrm{~m}$ ), multi-injection would also be necessary. For the CVD technique, upscaling has to be considered during the industrialization step.

\section{KINETIC MODELING OF COKE DEPOSITION}

\subsection{Kinetic Experimentation}

The kinetic study was carried out by LPT Gent:

- on 3 materials (HP-modified alloy, Incoloy $800 \mathrm{H}$, sintered $\alpha-\mathrm{SiC})$. The samples were in the shape of hollow cylinders

- and with 3 feedstocks:

\begin{tabular}{l|c|c|c}
\hline & $n$ - $\mathrm{C}_{6}$ & Mix I & Mix II \\
\hline$n$-hexane (wt\%) & 100 & 60 & 5 \\
$i$-octane & - & 20 & 85 \\
Me-cyclohexane & - & 10 & 5 \\
$o$-xylene & - & 10 & 5 \\
\hline
\end{tabular}

Mix I and Mix II feeds were used for varying the concentrations of certain coke precursors over a wider range so as to improve the accuracy of the kinetic parameters.

The temperature ranged from 800 to $950^{\circ} \mathrm{C}$, the conversion from 35 to $75 \%$.

\section{Main Results}

A comparison of the coking behaviour of the various alloys is presented in Figure 5. With $n$-hexane at $800{ }^{\circ} \mathrm{C}$ the coking rates on Incoloy $800 \mathrm{H}$ and on HP-modified alloy almost coincide. On Incoloy $800 \mathrm{H}$, however, the increase of the asymptotic coking rate with temperature is less pronounced than on HP-modified alloy.

Coking rates for the various feeds are compared in Figures 6 and 7 for Incoloy 800H and HP-modified alloy.

SEM study of the coked samples revealed that aromatic precursors have a tendency to form encapsulating coke. This tendency is also seen in steam reforming and corroborates the view that processes taking place during the catalytic stage (CO-formation, coke deposition) are similar to those occurring in steam reforming.

An EDX study of the coked samples showed that a surface layer of almost pure Cr-oxide is formed and that the main metal constituents in the coke layer are $\mathrm{Cr}$ and $\mathrm{Mn}$. Metals like $\mathrm{Ni}$ and $\mathrm{Fe}$ are present in small amounts only. These results are in accordance with EDX studies performed on samples of the tubes from industrial crackers and on samples of the coke produced in industrial crackers. This indicates that, in this regard, test studies in the microreactor are representative for industrial operation. 


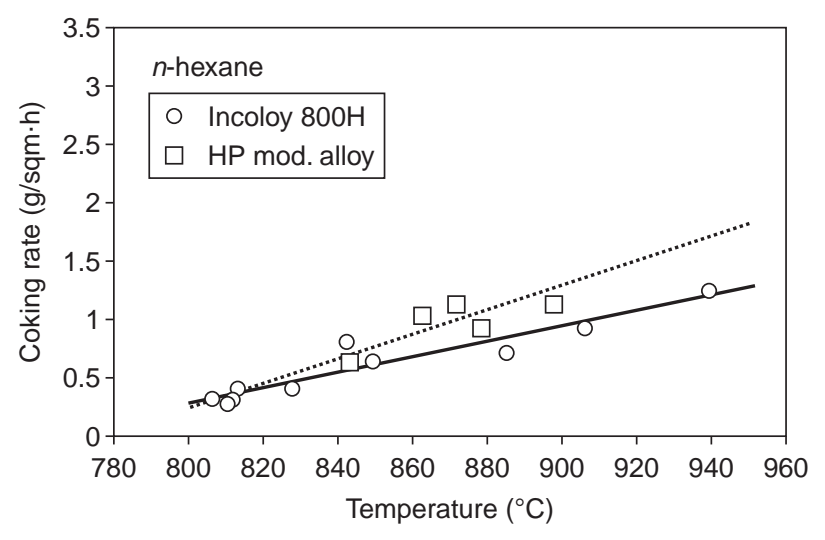

Figure 5

Coking rates vs temperature in $n$-hexane cracking for various alloys.

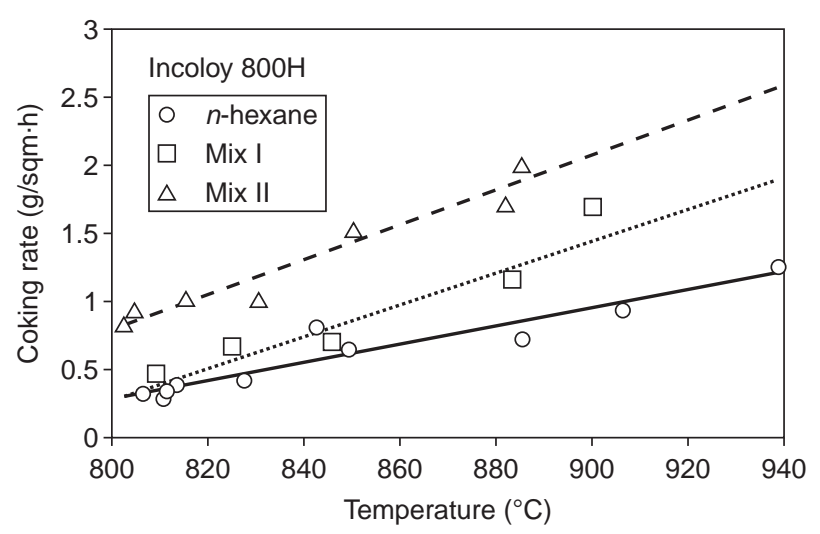

Figure 6

Coking rates on Incoloy $800 \mathrm{H}$ vs temperature for various feeds.

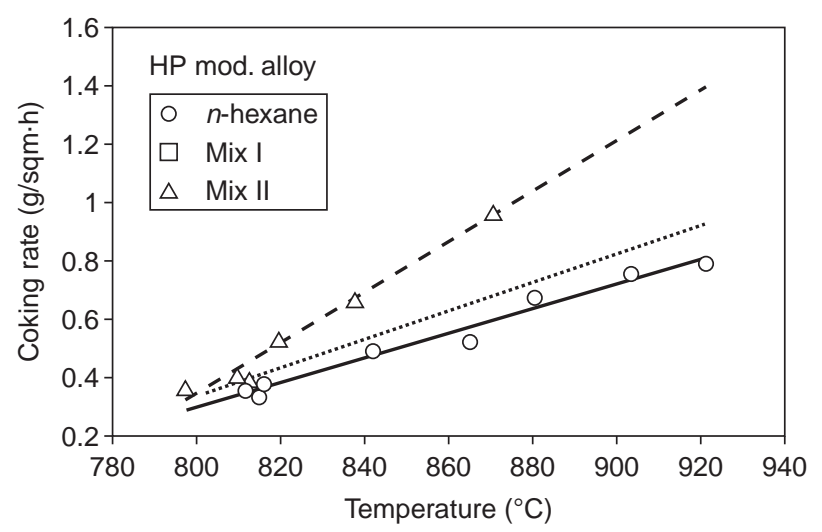

Figure 7

Coking rates on HP-modified alloy vs temperature for various feeds.

\subsection{Kinetic Modeling}

\subsubsection{State of the Art}

A literature survey showed that kinetic studies of coke formation have been hampered by an insufficient knowledge of the chemical pathways leading to coke and by a lack of reliable information concerning the reactivity of individual hydrocarbons: consequently, the models proposed for coke formation were mainly empirical [10-13].

Previous work carried out at LPT Gent by Sundaram et al. $[9,14]$ dealt with the kinetics of coking in thermal cracking of ethane and propane. The authors tested various simple models. After discrimination between the various models on the basis of statistical tests and an evaluation of the estimated activation energies, two kinetic models were proposed. One with ethylene as a precursor to describe the coke formation during ethane cracking and the other with propylene as a precursor to describe the coke formation during propane cracking. These models were found to be accurate for the description of coke formation in the cracking of pure ethane and pure propane. After that, Beyne [15], also at LPT Gent, dealt with the kinetics of coke deposition in the thermal cracking of mixtures of light hydrocarbons at temperatures ranging from 820 to $850^{\circ} \mathrm{C}$. Several models were considered with methane, ethylene, propylene, 1-pentene, benzene and toluene as precursors. A first order reaction of a single coke precursor, or a sum of two first order reactions and also a higher order reaction rate were used to improve the fit of the experimental results.

This work carried out at LPT Gent indicates that the quantitative description of coke deposition in the thermal cracking of various feeds with one model can not accurately be done by considering a sum of first or higher order reactions of a small number of arbitrarily chosen precursors. A more fundamental approach, based on a mechanistic interpretation of the process of coke deposition and a judicious choice of coke precursors, is necessary. Such a new fundamental approach was used in this project. It was derivated on the basis of the mechanism proposed below.

\subsubsection{Proposed Mechanism of Coke Formation}

The carbon deposition process during thermal cracking is a complex phenomenon, mainly consisting of:

- A heterogeneous catalytic mechanism (Fig. 8). The initial phase of coke deposition consists in the formation of a porous network of carbon filaments, catalysed by nickel and iron present on the surface of the reactor walls [16, 17]. Initially a hydrocarbon molecule is chemisorbed on a metal crystallite on the surface. The $\mathrm{CH}, \mathrm{CH}_{2}, \mathrm{CH}_{3} \ldots$ groups present on the surface loose hydrogen atoms which recombine and desorb into the gas phase. Carbon atoms formed at the surface dissolve in and diffuse through the metal particle thus causing a pressure build up at the 
dislocations and the grain boundaries that may exceed the tensile strength of the metal. A metal particle is then lifted from the surface and carbon crystallises at the rear end of this particle. A growing carbon stem thus develops which carries the crystallite at its top. Reactive carbon centerscontinue to exist along the filament skin from which lateral growth of filament occurs, creating a porous layer of interwoven filaments.

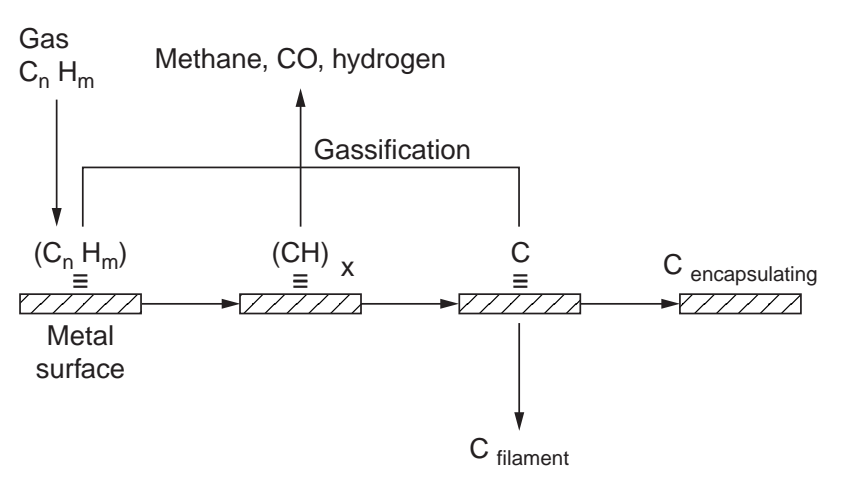

Figure 8

Carbon formation during the initial catalytic stage.

At the end of this phase, encapsulation of the metal particles decreases their catalytic activity and carbon formation slows down. Another mechanism of carbon formation then gains in importance.

The properties of the metal are very important in this mechanism. Hydrocarbon chemisorption depends on the chemical nature of the surface, and filaments formation depends on the solubility of the metal for carbon and is also affected by the roughness of the surface.

- A heterogeneous non catalytic mechanism: The heterogeneous non catalytic mechanism is the most important source of coke in a thermal cracker, since it operates practically throughout the complete run length. The coke in contact with the gas phase looks like a succession of discrete layers. Important coke precursors are unsaturated compounds (ethylene, acetylene, butadiene, etc.) and aromatics. The fact that no difference in relative rate constants was found for coke formation from a particular hydrocarbon on surfaces of different materials (Kopinke et al. $[18,19])$ supports the idea that the active centers are radical in nature and are located in the coke matrix. The number of radical sites on the coke surface depends on the gas phase composition and on the actual surface area of the coke layer. The coke macroradical then reacts by addition to unsaturated molecules and also to radicals from the gas phase. After dehydrogenation, graphitic layers with $\mathrm{sp}^{2}$ hybridization for C are formed [20].

- A homogeneous non catalytic mechanism: The homogeneous non catalytic mechanism, or gas phase coking, results from a sequence of molecular and/or radical reactions in the gas phase leading to high molecular weight polynuclear aromatic compounds which can be solid even at the high temperatures prevailing in the cracker coil. These soot particles may collide with the wall and integrate the coke layer. Nevertheless, it should be emphasized that gas phase coking contributes very little to coke formation in a thermal cracker, especially at gas phase temperatures below $900^{\circ} \mathrm{C}$ and with lighter feedstocks.

\subsubsection{Development of a Coking Model}

The modeling of coking concentrated on the asymptotic coking rate which corresponds to the non catalytic heterogeneous mechanism. This asymptotic coking rate can be measured during experiments performed in the electrobalance bench scale unit.

\section{Basis of the Coking Model}

The basis of the coking model is the presence of "active sites" on the coke surface. The coke layer mainly has a graphitic structure, so that the radical positions are influenced by the presence of aromatic rings which cause strong delocalisation of the $\pi$-electrons. In a first approximation, the reactivity of the various phenylic and benzylic positions is considered to be equal. It follows that only one type of reactive site on the coke surface has to be taken into account, keeping the number of parameters to be estimated within reasonable limits. Addition reactions at these sites regenerate the free radical position, so that the total number of active sites is constant. What then follows is a sequence of dehydrogenation and cyclisation reactions causing the incorporation of the carbon atoms of the coke precursors into the coke layer.

\section{Coke Precursors}

Since the number of species in the reaction mixture is very large, taking into account all the possible coking reaction paths would lead to an unrealistically high number of kinetic parameters and their estimation would be impossible or at least inaccurate. The number of reactions was decreased by restricting the number of coke precursors. The main precursors considered were olefins and aromatics.

\section{Coking Model}

The essential elements of the reaction of a precursor with an active site on the coke surface are:

- the growth of the coke layer with a number of carbon atoms equal to the carbon number of the precursor;

- the regeneration of the "active site" on the coke surface.

An example of such a reaction with ethylene as precursor can be written:

$$
n \mathrm{C}^{\bullet}+\mathrm{C}_{2} \mathrm{H}_{4} \rightarrow(n+2) \mathrm{C}^{\bullet}+2 \mathrm{H}_{2}
$$


and the corresponding rate equation for carbon formation:

$$
\mathrm{dC} / \mathrm{d} t=k_{\mathrm{C}_{2} \mathrm{H}_{4}}^{\prime} C_{\mathrm{C}_{2} \mathrm{H}_{4}}
$$

A similar approach for the other precursors leads to a coking mechanism containing $j$ reactions in parallel. The rate of coke formation may then be expressed as:

$$
\mathrm{dC} / \mathrm{d} t=\Sigma k_{j}^{\prime} C_{j}
$$

$2 j$ parameters have to be estimated: $j$ activation energies and $j$ frequency factors. This number can be further reduced. Since only one type of active site is considered, the differences in reactivity are mainly due to the precursors. For components with the same functional group, the activation energy for coke formation is considered to be equal.

Accordingly, coke precursors were classified into 6 different groups:

- triple bonds (acetylene, methylacetylene);

- double bonds (ethylene, propylene, 1-butene, $i$-butene);

- conjugated double bonds (butadiene, cyclopentadiene);

- aromatics (benzene);

- branched aromatic (toluene, xylene);

- aromatic olefin (styrene).

A reference component is chosen in each group. The reference factor for the coke formation from the other members of the group can then be related to that of the reference component through the relative reactivities for coke formation (Kopinke et al. [19]). This leads to a coking model containing 12 parameters: 6 frequency factors and 6 activation energies.

Although in an industrial unit the transient phase during which the catalytic coking mechanism is predominant is short with respect to the total run length of the furnace, the implementation of the catalytic effect was envisaged. Nickel or in general a transition metal acts as a catalyst. Catalytic carbon formation can be modelled in terms of what is done in steam reforming [21].

\subsubsection{Coking Models}

Modeling of the coking rate on 2 metallic materials was achieved by LPT Gent.

The parameters for the kinetic model were estimated using the experiments performed in the electrobalance bench scale unit.

Figures 9 and 10 present the parity plot for Incoloy $800 \mathrm{H}$ and HP-modified alloy respectively. For these 2 materials, the fit between experimental and calculated values is very good.

\section{CONCLUSIONS}

The following achievements can be reported:

- coating of HP-modified alloy by plasma spraying, packed cementation, CVD;

- development of a methodology to evaluate the behavior of the coatings with respect to thermal shocks;

- development of a methodology to evaluate the coking behavior of the coatings;

- design and construction of an experimental set up for kinetic experimentation on coking;

- modeling of the coke deposition rate on 2 different superalloys.

Under reference conditions, very low coking rates were observed with the following coatings:

- chromium packed cementation coating: $0.25 \mathrm{~g} / \mathrm{m}^{2} \mathrm{~h}$;

- TiC + SiC CVD coated samples: $0.3 \mathrm{~g} / \mathrm{m}^{2} \mathrm{~h}$;

- whereas for the substrate the coking rate was $0.9 \mathrm{~g} / \mathrm{h} / \mathrm{m}^{2}$.

A correlation between the coking behaviour and the microstructural characteristics (porosity, adhesion) was observed.

The flat samples geometry needed by the coking test micropilot gave rise to difficulties in obtaining good quality

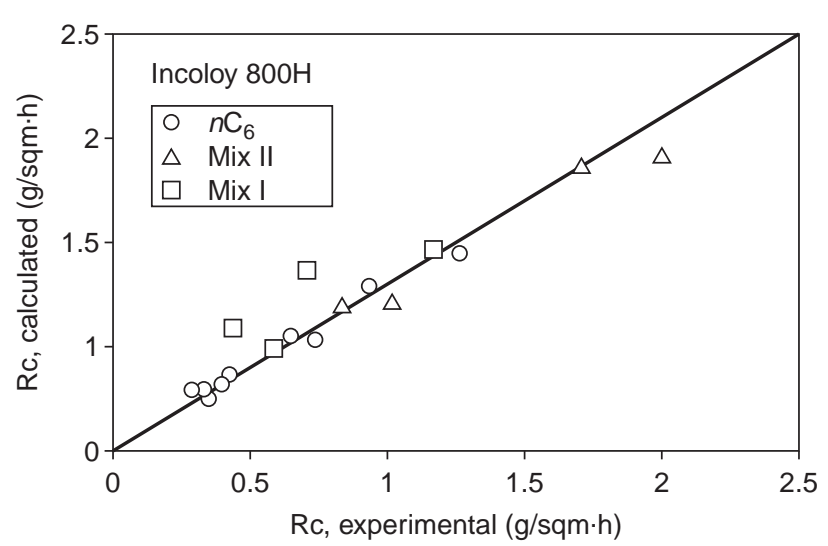

Figure 9

Parity plot for Incoloy $800 \mathrm{H}$.

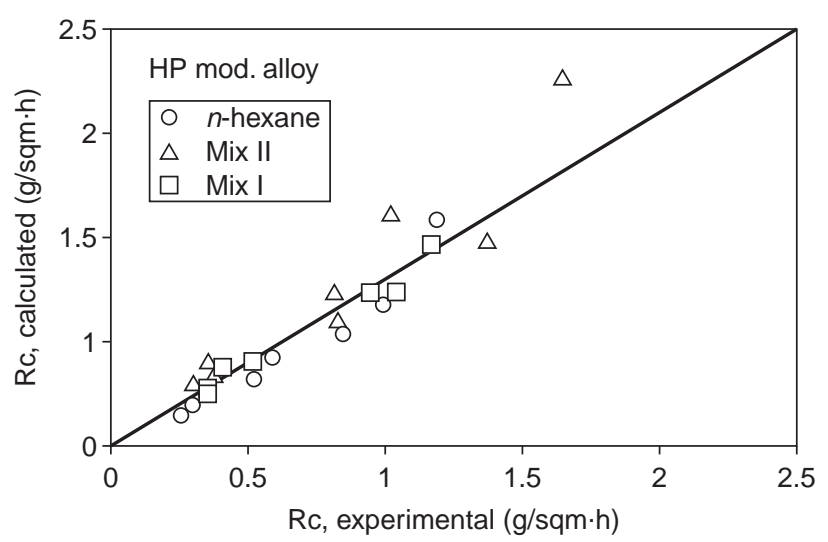

Figure 10

Parity plot for HP-modified alloy. 
coating, especially for plasma spraying. These coatings could not be evaluated from the standpoint of coking behavior. The analysis of plasma sprayed coatings microstructure indicated that surface morphology may have a stronger effect on the coking rate than the material itself. Moreover, surface contamination may also modify the coking behaviour and induce a scatter in the coking test results. Thermal tests carried out on coated tube elements and rings showed that, for plasma sprayed coating, adhesion is too weak for industrial application.

Upscaling the CVD technique would have to be investigated further.

The most promising technique is packed cementation and IFP plans to carry out a pilot test as soon as the feasibility of inner coating of tubes 1 meter in length is confirmed.

\section{ACKNOWLEDGMENTS}

The authors are grateful to the Commission of the European Communities for funding this research project and also to the other partners involved in this project for their own contribution.

\section{REFERENCES}

1 Brite-Euram Contract BRE2-CT92-0190 (1997) Anticoking Coatings for High Temperature Petrochemical Reactors. Final Report, July 31, 1997.

2 Brown, J., Broutin, P. and Ropital, F. (1998) Coke Deposition under Steam Cracking $C$ onditions. Study of the Influence of the Feedstock Conversion by Micropilots Experiments. Paper presented at EFC Workshop Carburization Metal Dusting Carbon Deposition, Francfort, D, November 6-7, 1997. Materials and Corrosion, 49, 360-366.

3 Parks, S.B. and Schillmoller, D (1985) Use these Alloys to Improve Ethylene Production, Stainless Steel World, November 1985, 27-35.

4 Froment, G.F. (1990) Coke Formation in the Thermal Cracking of Hydrocarbons. Review Chem. Eng., 6, 4, 293328

5 Billaud, F, Guéret, C, Broutin, P. and Weill, J. (1992) Coke Formation During Hydrocarbons Pyrolysis. Revue de l'Institut français du pétrole, 47, 4, 537-549.
6 Cairns, J., Coad, J., Richard, E. and Stenhouse, I. (1980) Carbon Deposition on Metallic Surfaces Studied by r.f. Plasma Discharge. Nature, 288, 5792, 686-687.

7 Horsley, G. and Cairns, J. (1984) The Inhibition of Carbon Deposition on Stainless Steel by Prior Selective Oxidation. Applications of Surface Science, 18, 273-286.

8 Baikley, D. and Jorgensen, N. (1990) Studies of Catalytically Enhanced Carbon Deposition and Removal using a Gas Plasma System. Catalysis Today, 7, 277-286.

9 Sundaram, K.M. and Froment, G.F. (1979) Kinetics of Coke Deposition in the Thermal Cracking of Propane. Chem. Eng. Sc., 34, 635-644.

10 Shah, Y.T., Stuart, E.B. and Sheth, K.D. (1976) Coke Formation during Thermal Cracking of $n$-octane. Ind. Eng. Chem. Process Des. Dev., 15, 518-524.

11 Albright, L. and Marek, J.C. (1988) Coke Formation During Thermal Cracking of $n$-octane. Ind. Eng. Chem. Res., 27, 755-759.

12 Sahu, D. and Kunzru, D. (1988) Effect of Benzene and Thiophene on Rate of Coke Formation During Naphtha Pyrolysis. Can. J. Chem. Eng., 66, 808-813.

13 Pramanik, M. and Kunzru, D. (1984) Coke Formation in the Pyrolysis of $n$-hexane. Ind. Eng. Chem. Process Des. Dev., 24, 1275-1281.

14 Sundaram, M. (1981) Coke Deposition in the Thermal Cracking of Ethane. AIChE J., 27, 946.

15 Beyne, A. (1986) Internal Report LPT.

16 Baker, T.K. and Chludzinski, J.J. (1980) Filamentous Carbon Growth on Nickel-Iron Surface. J. Catal., 64, 464-478.

17 Figueiredo, J.L. (1989) Filamentous Carbon. Erdöl und Kohle-Ergasd-Petrochem., 42, 294-297.

18 Kopinke, F.D., Zimermann, G. and Nowak, S. (1988) On the Mechanism of Coke Formation from Hydrocarbons in Steam Cracking: Conclusions from Results Obtained by Tracer Experiments. Carbon, 26, 2, 117-124.

19 Kopinke, F.D, Zimmermann, G., Reyniers, G.C. and Froment, G.F. (1993), Relative Rates of Coke Formation from Hydrocarbons in Steam Cracking of Naphtha. Ind. Eng. Chem. Res., 32, 1, 56-60.

20 Reyniers G.C., Froment, G.F., Kopinke, F.D. and Zimmermann, G. (1994) Coke Formation in the Thermal Cracking of Hydrocarbons: Modeling of Coke Formation in Naphtha Cracking. Ind. Eng. Chem. Res., 33, 2584-2590.

21 Swoeek, J.W., Froment, G.F. and Fowles, M. (1997) Journal of Catalysis., 169, 250-262.

Final manuscript received in May 1999 